\title{
Positron and nanoindentation study of helium implanted high chromium ODS steels
}

\author{
Jana Simeg Veternikova*, Martin Fides ${ }^{* *}$, Jarmila Degmova*, $^{*}$ \\ Stanislav Sojak*, Martin Petriska*, Vladimir Slugen*
}

\begin{abstract}
Three oxide dispersion strengthened (ODS) steels with different chromium content (MA 956, MA 957 and ODM 751) were studied as candidate materials for new nuclear reactors in term of their radiation stability. The radiation damage was experimentally simulated by helium ion implantation with energy of ions up to $500 \mathrm{keV}$. The study was focused on surface and sub-surface structural change due to the ion implantation observed by mostly non-destructive techniques: positron annihilation lifetime spectroscopy and nanoindentation. The applied techniques demonstrated the best radiation stability of the steel ODM 751. Blistering effect occurred due to high implantation dose (mostly in MA 956) was studied in details.

K e y w o r d s: ODS steels, helium ion implantation, nanoindentation, vacancy defects
\end{abstract}

\section{Introduction}

In this paper, the new perspective materials - oxide dispersion strengthened (ODS) steels with high chromium content are investigated as possible candidates for construction of fuel cladding and internal components mostly in reactors with more aggressive chemical environment. These steels are typical by high strength and thermal resistance. Due to higher chromium content (between 14$20 \mathrm{wt} \% \mathrm{Cr}$ ) they have also better corrosion resistance than well-known ODS steels with $9 \mathrm{wt} \%$ of chromium, ie ODS Eurofer.

The high chromium ODS steels have already been tested couple times to radiation resistance by many ways [1-3]. The investigation of complex materials is quite difficult and sensitive task due to their complicate and inhomogeneous structure, thus the examination of model alloys has been mostly preferred round the world [4-6]. Therefore, there is only few papers comparing more commercial ODS steels at the same time in term of their radiation stability or only couple works with application of surface nondestructive techniques for their study.

Our work was focused on the irradiation of the commercial ODS steels (MA 956, ODM 751 and MA 957) by helium ions and study of their microstructural changes in term of vacancy defects and hardness measurements up to the depth of $1.5 \mu \mathrm{m}$. The main purpose of our work was to qualify the investigated materials in term of their radiation stability and to consider applicability of the used techniques.

\section{Investigated samples}

The investigated samples were prepared from the three different high chromium ODS steels MA 956, MA 957 and ODM 751 obtained as commercial products of different international metal corporations.

Table 1. Chemical composition of investigated ODS steels in wt\%

\begin{tabular}{lccc}
\hline Alloys & $\begin{array}{c}\text { MA 956 } \\
\text { (Incoloy) }\end{array}$ & $\begin{array}{c}\text { ODM 751 } \\
\text { (INCO) }\end{array}$ & $\begin{array}{c}\text { MA 957 } \\
\text { (Dour Metal) }\end{array}$ \\
\hline $\mathrm{C}$ & 0.03 & 0.07 & 0.03 \\
$\mathrm{Mn}$ & 0.06 & 0.07 & 0.09 \\
$\mathrm{Si}$ & 0.05 & 0.06 & 0.04 \\
$\mathrm{Ni}$ & 0.11 & 0.02 & 0.13 \\
$\mathrm{Cr}$ & 21.7 .2017 & 16.1 .2017 & 13.7 .2017 \\
$\mathrm{Mo}$ & 0.05 & 1.7 .2017 & 0.03 \\
$\mathrm{Ti}$ & 0.33 & 0.7 & 0.98 \\
$\mathrm{Al}$ & 1.5 .1977 & 3.8 .2017 & 0.03 \\
$\mathrm{O}$ & 0.21 & 0.21 & 0.21 \\
$\mathrm{Y}$ & 0.38 & 0.38 & 0.38 \\
\hline
\end{tabular}

The chemical composition of the investigated steels was tested by optical emission spectroscopy at the Welding Research Institute in Bratislava and is listed in Table 1.

The steels were prepared by the standard processes of sintering and mechanical alloying defined by the producers. The samples were prepared from as-received material

\footnotetext{
* Institute of Nuclear and Physical Engineering, Faculty of Electrical and Information Technology, Slovak University of Technology, Ilkovičova 3, 81219 Bratislava, Slovakia, jana.veternikova@stuba.sk, ** Institute of Materials Research, Slovak Academy of Sciences, Watsonova 47, 04001 Košice, Slovakia
} 
by cutting the steel sheets into suitable pieces with diameter $10 \times 10 \times 0.8 \mathrm{~mm}^{3}$. In order to remove surface impurities, the sample surfaces were polished after the cutting almost into a mirror level. The zone affected by cutting usually goes around $150 \mu \mathrm{m}$ [7], but subsequent grinding removes the most affected subsurface and the powder used for polishing of our samples had particles with size of $0.5 \mu \mathrm{m}$. The roughness of the as-received samples surface measured by atomic force microscopy achieved up to $50 \mathrm{~nm}$, thus the influence of the sample preparation is probably for the subsurface techniques minimal.

\section{Experimental treatment and methods}

The samples were loaded by radiation damage performed at a linear accelerator belonging to the Institute of Nuclear and Physical Engineering, Slovak University of Technology. Helium ions $(\mathrm{He} 2+)$ with a kinetic energy up to $500 \mathrm{keV}$ were implanted into the samples. The implantation temperature achieved maximum of $62{ }^{\circ} \mathrm{C}$; therefore it has no effect on the structure. The implantation depth was up to $1.2 \mu \mathrm{m}$ according to SRIM calculation [8]. The implantation level was $\sim 10^{18}$ ions $\mathrm{cm}^{-2}$ and the maximum radiation damage, calculated from the average number of vacancies in $1 \mathrm{~cm}^{2}$ of material obtained by SRIM, was around 45 dpa for the damaged zone.

During the ion implantation, point defects accumulate into the structure as a result of the atom knocking-on by the helium nuclei [9]. Therefore accumulation of small vacancy defects typical for ferritic structure was assumed in the investigated steel which is commonly leading to an increase of the hardness.

The samples were investigated by positron annihilation spectroscopy (PALS) sensitive to small vacancy defects and to their changes in size or concentration due to the radiation strain. The PALS measurements were done in a fast-fast mode [10] with the FWHM parameter close to $200 \mathrm{ps}$. The variance of fit (reduced chi-square) achieved value in range of $\langle 1 ; 1.2\rangle .{ }^{22} \mathrm{Na}$ in a Kapton foil with the energy up to $540 \mathrm{keV}$ was used as the PALS positron source. The PALS can determine defect size and defect concentration in the investigated samples up to a depth of $120 \mu \mathrm{m}$. According to published research of $\mathrm{V}$. Krsjak [11] approximately $14 \%$ of positrons can give information about the defects in the layers up to $800 \mathrm{~nm}$ and the change of structure due to implantation can be so visible there. Our implantation depth and irradiation dose is higher, for that we assumed good applicability of this technique for our intention.

The measurement of nanoindentation was performed at Slovak Academy of Sciences by Agilent Nano Indenter G200 hardness tester at room temperature. The tests were evaluated by the standard method of Oliver and Pharr [12]. The Berkovich indenter was used for hardness measurement (HIT) up to the depth of $2000 \mathrm{~nm}$ with velocity of $30 \mathrm{~nm} / \mathrm{s}$. The applied load was approximately up to $600 \mathrm{mN}$ and 16 depth profiles were measured from which average values of hardness were calculated.

\section{Results and Discussion}

After the implantation, the hardness increase $\left(\Delta H_{I T}\right)$ was quite well visible in the steels MA 957 and ODM 751 (up to 20\%), but no changes were observed in MA 956 (Fig. 1). The values of hardness for the MA 957 have bigger dispersion (mostly in the non-implanted state) which can demonstrate bigger structural inhomogeneity than for the other investigated steels. The achieved hardness values were almost similar in the surface up to $100 \mathrm{~nm}$ (between 6 and $7 \mathrm{GPa}$ ) and from the layers deeper than $1.1 \mu \mathrm{m}(\approx 4 \mathrm{GPa})$ for all types of steels (implanted and non-implanted). The change of hardness due to the implantation was distinctive only between 0.1 and $1.1 \mu \mathrm{m}$.

The observed hardness is not very different for steels with different chromium content, although more chromium commonly means more precipitates supporting hardness and brittleness. This is not found here probably due to negligible content of carbon or other elements forming the precipitates. However the differences in the depth profile are evident. It is important to have in mind that the profiles can differ in the same steels for the individual samples, as ODS steels are inhomogeneous
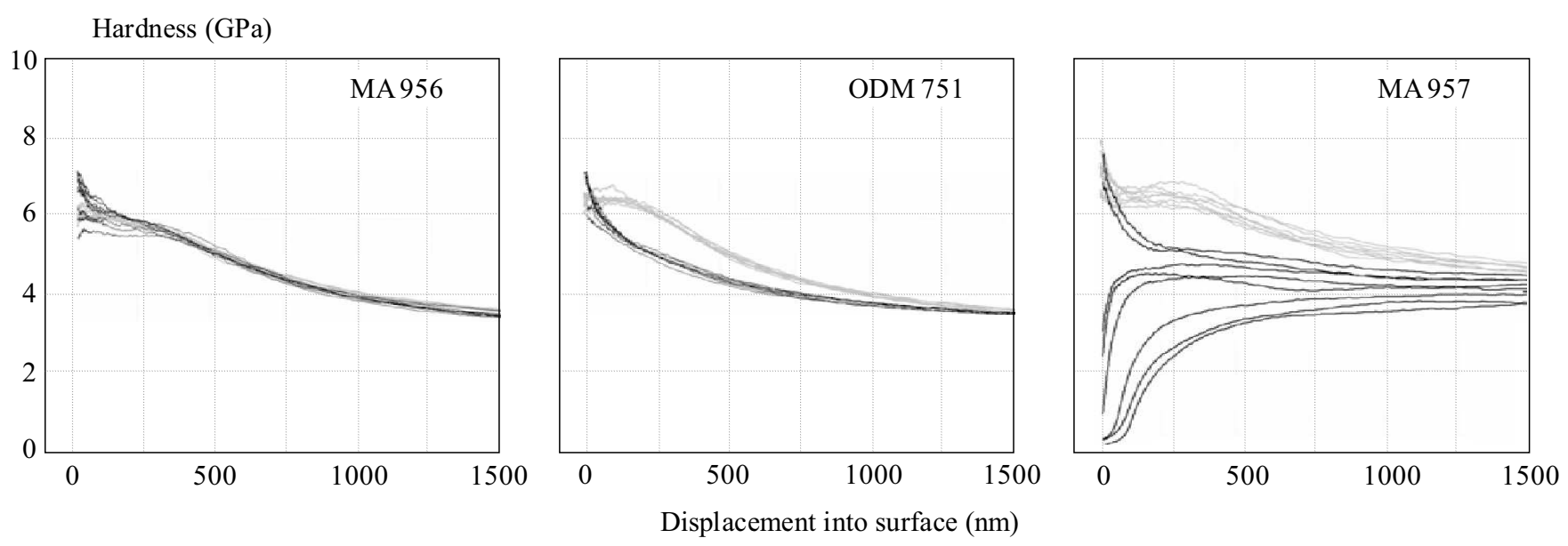

Fig. 1. Hardness depth profile: light lines - implanted, dark lines - non-implanted 

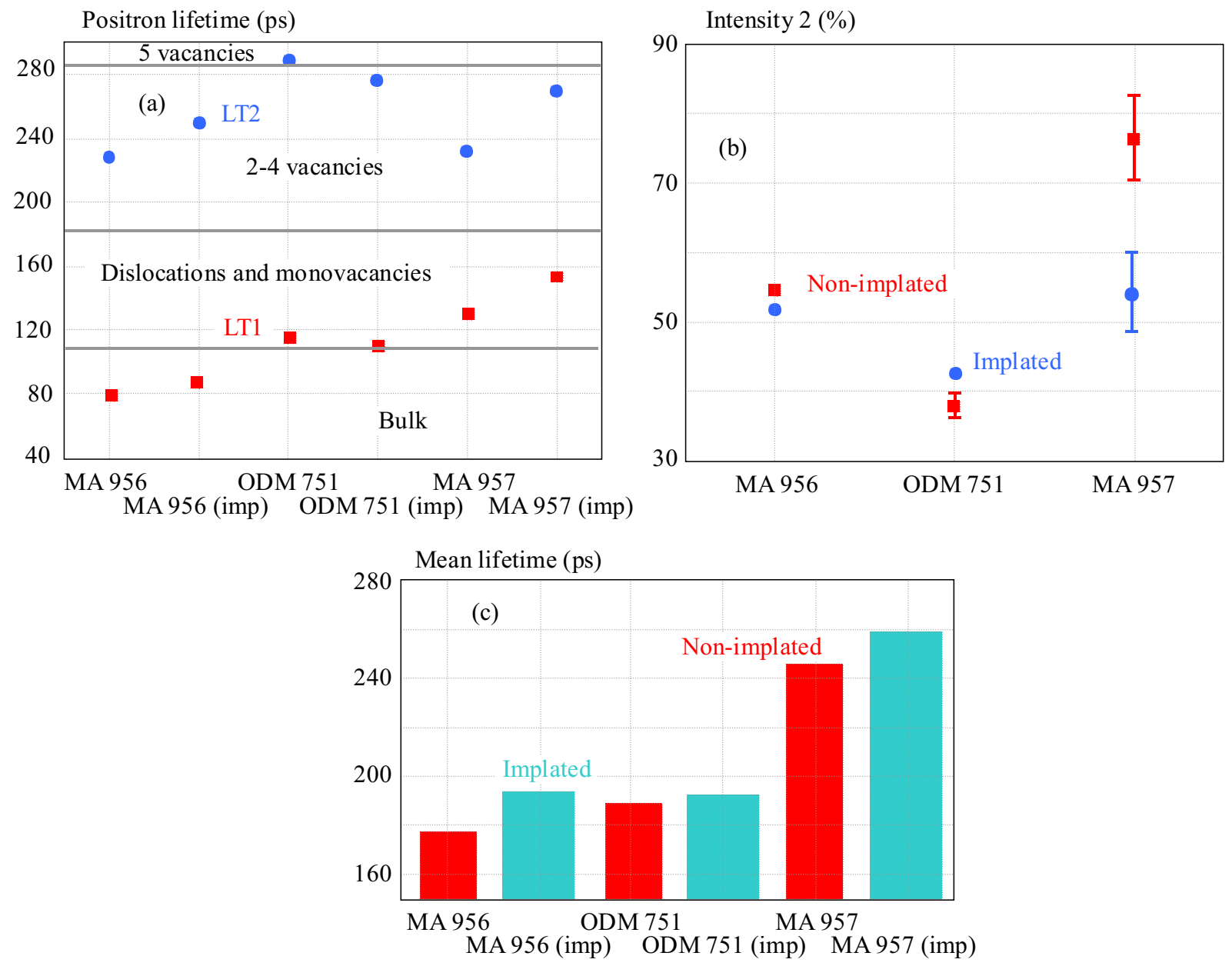

Fig. 2. PALS results, (a) - LT2 characterizing defect size, (b) - intensity 2 for defect concentration, and (c) - mean lifetime describes the total defect presence

materials (seen for MA 957). For that reason, it is necessary to perform more measurements for both states the implanted state as well as the non-implanted one.

The results of hardness demonstrated the best resistance to radiation damage for MA 956. The average value of its hardness in the whole profile has in principle no increase due to the implantation (about $0.2 \pm 1.6$ ), but this sample have been at the same time affected by blistering effect [13] removing the first surface layers in some part of the sample (probably in the area of the hardness measurement too). Consequently the hardness measurement could be influenced by this effect, and then this steel could have been actually the most radiation damaged in compare to others, although the results seem to be the best one. For the closer view, application of further techniques was needed (application of PALS seemed to be sufficient). The increase of the average hardness calculated from 16 measurements was: $0.7 \pm 0.5$ for ODM 751 and $2.5 \pm$ 1.9 for MA 957.

The PALS results (Fig. 2) showed small change of defect size after the implantation (LT2), but defect concentration (Intensity 2) does not strictly growth as was firstly assumed. The size of defects slightly increased, mostly for the MA 957 from three-vacancies almost to the fivevacancies in predominance. Defects in ODM 751 probably stayed stable five-vacancies before and after the implantation. The MA 956 showed the increase of some defects from three-vacancies into four-vacancies and after the implantation there is probably mixture of three and fourvacancies in predominance. The defect presence in the MA 957 seems to be saturated as values of the LT1 is in the area of dislocations and mono-vacancies (LT1 commonly describes the bulk value $\approx 110 \mathrm{ps}$ ). The LT1 of the MA 956 is characterized as the reduced bulk according to the Standard trapping model [14]. The ODM 751 contains probably some shallow traps as its value is only little over the bulk value. The difference in presence of the small defects is caused probably by the additional thermal treatment during the process of manufacture, where the steel MA 956 and ODM 751 were recrystallized after the production. The steel MA 957 was only partially or not recrystallized and so it can still contain a lot of small defects not annealed after the production.

For the steel ODM 751, the defect concentration increased but for other steels decreased, which can be a sign for defect merging due to the implantation: the 
size slightly increased but the concentration decreased. It means that diffusion processes in these two steels - MA 956 and MA 957 still works even without increasing a temperature.

The Mean lifetime (MLT), proportional to total defect presence/volume, demonstrated increase of its values. Therefore the defects were really accumulated in the structure, even though the individual lifetimes did not indicate it clearly. The MLT is calculated as mean value of all lifetimes weighted by their intensities. This value is so loaded only by measurement error. The ODM 751 showed small change only $3 \mathrm{ps}$, but it is also evidence of some structural changes as the deviation is considered up to 2 ps. The most significant change was for MA 956 with the growth of $16 \pm 2 \mathrm{ps}$. It is followed by MA 957 with the increase of $14 \pm 2$ ps. On account of the error bars, this positron result for MA 956 and MA 957 is similar.

\section{Conclusion}

The experimental positron annihilation results showed better resistance to the defect accumulation in the ODM 751 and the bigger sensitivity of MA 957 and MA 956. The hardness depth profile showed small divergence, but it is probably caused by the blistering effect - the removing of surface layers as the most distinctive sign of radiation damage. The onion skin grain structure together with $16 \mathrm{wt} \% \mathrm{Cr}$ seems to be the best in compare to partiallyrecrystallized or fully recrystallized steels with lower (14 wt $\%$ ) or higher (20 wt\%) chromium content. The structure of the steel ODM 751 seems to be optimal due to its mechanical, thermal and probably also radiation resistance in comparison to our investigated steels.

Our research proved that these two so-called nondestructive techniques - positron annihilation spectroscopy and nanoindentation can be effectively applied together for new information and their syntheses and comparison, because their results are mostly in agreement as they observe microstructure influenced mostly by the same factors (defects and precipitations). On the other hand, they are also supplementary as they describe the factors in different ways.

Although, the positron annihilation spectroscopy is less sensitive to the surface layers up to $1.2 \mu \mathrm{m}$ where the radiation influenced zone was, it also found some small changes in the structure of the investigation steels similar to the hardness measurements. Though positron annihilation spectroscopy is not fully optimal for investigation of surface layers, with application of other technique can be useful and give supplementary information about the structure. For the deep PALS near surface region studies the pulsed low energy positron systems (available at FRM II facility in Garching, Germany) could be used in future.

\section{Acknowledgements}

This work was supported by Slovak National Grant VEGA 1/0104/17, VEGA 1/0477/16 and VEGA 1/0339/ 16. The nanoindentation testing was supported by the project APVV 0108-12 ConCer.

\section{REFERENCES}

[1] M. A. Pouchon, J. Chen, M. Dobeli and W. Hoffelner, "Oxide dispersion strengthened steel irradiation with helium ions", $J$. Nucl. Matter., 352 (2006) 5761.

[2] K. Yutani, H. Kishimoto, R. Kasada and A. Kimura, "Evaluation of Helium effects on swelling behavior of oxide dispersion strengthened ferritic steels under ion irradiation", J. Nucl. Matter., 367370 (2007) 423427.

[3] M. B. Toloczko, F. A. Garner and S. A. Maloy, "Irradiation creep and density changes observed MA 957 pressurized tubes irradiated to doses of $40110 \mathrm{dpa}$ at 400750 C FFTF", J. Nucl. Matter., 428 (2012) 170175.

[4] D. A. Mcclintock, M. A. Sokolov, D. T. Hoelzer and R. K. Nanstad, "Mechanical properties of irradiated ODSEUROFER and nanocluster strengthened 14YWT", J. Nucl. Matter., 392 (2009) 353359.

[5] H. Kishimoto, K. Yutani, R. Kasada, O. Hashitomi and A. Kimura, "Heavyion irradiation effects on the morphology of complex oxide particles oxide dispersion strengthened ferritic steels", J. Nucl. Matter., 367370 (2007) 179184.

[6] N. Baluc, J. L. Boutard, S. L. Dudarev, M. Rieth, J. Brito Correia, B. Fournier, J. Henry, F. Legendre, T. Leguey, M. Lewandowska, R. Lindau, E. Marquis and A. Munoz and B. Radiguest and Z. Oksiuta, "Review on the EFDA work programme on nanostructured ODS RAF steels", J. Nucl. Matter., 417 (2011) 149153.

[7] P. Hodorek, J. Dryzek and M. Wrobel, "Positron Annihilation Study of Defects Induced by Various Cutting Methods Stainless Steel Grade 304", Tribol Lett., 45 (2012) 341347.

[8] J. F. Ziegler, The stopping and range of ions solids, Pergamon, New York, 1985, pp. 321.ISBN 13: 9780080216034.

[9] G. Kinchin and R. Pease, "The displacement of atoms solids by radiation", Rep. Progr. Phys., 18 (1955) 151.

10] M. Petriska, A. Zeman, V. Slugen, V. Krsjak, S. Sojak, DEBARBERIS and L, "Application of FastDigitizer Card Acqiris DP240 Positron Lifetime Spectroscopy", Phys. Stat. Solidi., C 60 (2009) 24652467.

[11] V. Krsjak, "Positron annihilation study of advanced nuclear reactor materials", Doctoral thesis, FEI STU, Bratislava, September, 2008.

[12] W. C. Oliver and G. M. Pharr, "An improved technique for determining hardness and elastic modulus using load and displacement sensing indentation experiments", J. Mater. Res., 7 (1992) 156483.

[13] J. Simeg-Veternikova, "Study of materials for advanced reactor systems, LAP, Lambert, Saarbrucken, Germany, 2015, pp. 129.ISBN 978659758232.

14] R. Leipner and S. H. Krauserehberg, Positron annihilation Semiconductors, second ed., Springer, Berlin, 1998.ISBN 3540643710.

Received 23 April 2017 